\title{
Decomposing inequality changes in Uruguay: the role of formalization in the labor market
}

Verónica Amarante*, Rodrigo Arim and Mijail Yapor

\author{
* Correspondence: \\ veronica.amarante@cepal.org \\ Rodrigo Arim and Mijail Yapor are \\ consultants for the Economic \\ Commission for Latin America and \\ the Caribbean, they do not work \\ there permanently. \\ Economic Commission for Latin \\ America and the Caribbean, \\ Santiago, Chile
}

\begin{abstract}
During the first decade of the twentieth century, the Uruguayan labor market showed a significant decline in wage inequality and in the incidence of labor informality, while similar changes also took place in other Latin American countries. These trends were observed in a period of strong economic dynamism. Most extended explanations for this declining inequality in the region have been centered on falling returns to education. The main goal of this paper is to present new evidence on the relation between informality and wage inequality through a RIF-based regression decomposition analysis which, besides confirming the relevant role of education, shows that the process of labor market formalization also played a significant role in the reduction of inequality in Uruguay, mainly through a price effect.

JEL Classification: D31, J31

Keywords: Inequality, Informality, Microeconometric decompositions
\end{abstract}

\section{Introduction}

A significant reduction in informality-measured as the share of workers who do not contribute to the social security system-was probably one of the main changes in the Uruguayan labor market during the last decade. In 2001, 36 \% of workers did not contribute to social security even though this contribution was mandatory for everyone. This share increased in the following years, reaching $41 \%$ in 2004. The trend then reversed in 2005 , and after many years of decline, informality fell to $24 \%$ in 2013 . The overall decline in informality is mainly explained by the behavior of private employees, whose informality rate went from $28 \%$ in 2001 to $13 \%$ in 2013 (Table 4 in the Appendix). This significant decline in informality is probably related both to the sustained cycle of economic growth that the Uruguayan economy experienced during the period and to a set of relevant institutional changes that took place simultaneously.

On the wage side, a significant decline took place during the recession and economic crisis that the country faced at the beginning of the twenty-first century. Its recovery was slower than that of economic activity: wages began to grow in 2005 and only got back to their pre-crash level in 2010. This average evolution was the result of different changes along the wage distribution, which led to a strong decline in all wage inequality indices after 2006 (Table 5 in the Appendix). Up to now, the link between informality

(c) 2016 The Author(s). Open Access This article is distributed under the terms of the Creative Commons Attribution 4.0 International License (http://creativecommons.org/licenses/by/4.0/), which permits unrestricted use, distribution, and reproduction in any medium, provided you give appropriate credit to the original author(s) and the source, provide a link to the Creative Commons license, and indicate if changes were made. 
and inequality had not been systematically studied. Thus, the main purpose of this paper is to underline the importance of this relation and the potential role of informality, given that the existing literature on wage inequality has focused on other characteristics of wage setting, such as the impacts of human capital or regional disparities.

Previous research indicates that the main explanatory factor for this decline of inequality has been the narrowing of the wage gap by educational level, as it happened in other countries in the region. The increase in employment and the decline in regional inequalities have also played a role in inequality decline, although a somewhat smaller one (see Amarante et al. 2014; Alves et al. 2012; Llambí and Perera 2014; among others). The change in educational attainment has had a minor contribution, which highlights a major weakness that the country faces. The literature has paid less attention to institutional features of the labor market, although the increase in the minimum wage has been mentioned as an element that may have contributed to labor income equality (see for example, ECLAC 2014).

These two main features that arise from the description of the Uruguayan labor market took place with slightly different schedules: while informality began to decline in 2004, wage inequality continued to rise until 2007, before starting to decline (Fig. 1). Nevertheless, both phenomena may be related, and the objective of this article is to explore this potential link.

Theoretically, the fall in informality could be related to wage inequality in different ways, depending on the magnitude of the change, the relative weight of the formal and informal sectors, the level of inequality within each sector, and the income differential between sectors. Disentangling the nature of this link is not easy, especially in a context like the Uruguayan one during the years we studied, which were marked by significant economic growth and simultaneous changes at the institutional, political, and economic levels. In such a context, informality cannot be claimed to be exogenous, and its effect should be interpreted as reflecting that of labor market institutions. In spite of this, we argue that we can shed light on this link by applying microeconometric decompositions to describe the main features of wage inequality changes, and by including formality among the explanatory factors. Based on the methodology proposed by Firpo et al. (2011), we compute the differential effects of various variables across the wage distribution and isolate the contribution of each variable. The article is organized as follows. First, we briefly discuss the relationship between inequality and informality (Section 2).

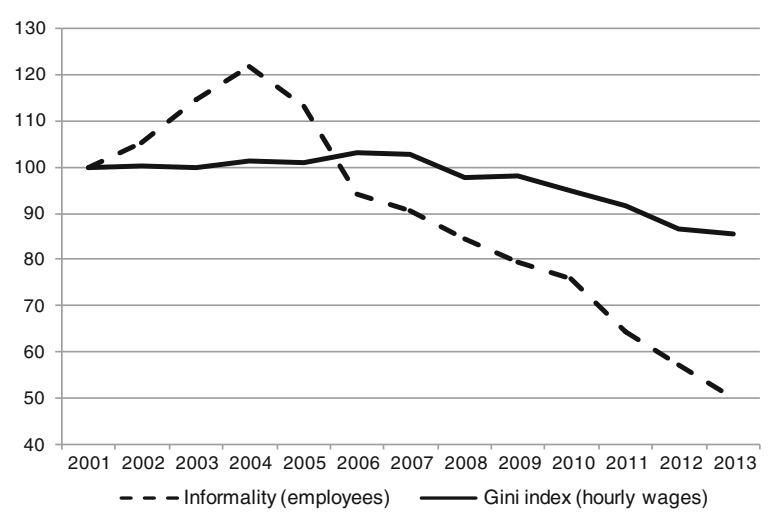

Fig. 1 Evolution of labor informality and inequality. 2001-2013. Source: based on household surveys 
After that, we summarize recent policies that may have directly or indirectly affected informality evolution in Uruguay, and summarize the main factors that the literature has identified as potential explanations for inequality decline (Section 3). We then describe our methodology (Section 4) and present our main results (Section 5). Finally, we present our conclusions (Section 6).

\section{Motivation: informality and inequality}

Most developing economies are characterized, among other things, by sizeable informal employment (see for example Schneider 2012; Tornarolli et al. 2014; among others). In many of these countries, the level of income inequality is also substantial and mainly determined by high labor income inequality. Despite these two clear features, the literature addressing the informality-inequality relationship is relatively scarce, probably due to the substantial problems related to endogeneity and omitted variables, as discussed below.

Indeed, one may argue that inequality contributes to informality, but it could also be the case that informality leads to inequality-reverse causation. For instance, the model proposed by Chong and Gradstein (2007) is consistent with the first explanation. They show that increases in income inequality-induced by decreases in the relative returns to formality for the poor-lead to a greater informal sector and that this effect is higher when institutions are weak. Similarly, Mishra and Ray (2013) argue that an increase in income inequality fosters demand for informal sector goods, thus providing support for a positive inequality-informality relationship for developing countries. A related strand of the literature emphasizes the link between high informality and lower tax revenue (Loayza 1996; Johnson et al. 1998; Shneider and Enste 2000; among others). This, in turn, can affect the State's ability to redistribute both directly and indirectly through education, which can have a direct impact on inequality. This type of argument has been incorporated by Rosser et al. $(2000,2003)$ for example, who also find a positive correlation between informality and the Gini coefficient in transition economies, and explicitly recognize that different causal mechanisms may operate in both directions. Binelli and Atanassio (2010), using microdata for Mexico, show that wage inequality is much higher among informal workers and that changes in the size of the informal sector closely follow changes in wage inequality. In a later paper, Binelli (2016) - based on Mexican evidence-suggests that higher wage dispersion is one of the channels through which informality negatively affects development. Therefore, despite the presence of methodological difficulties in identifying casual links and the scarce literature about this topic, there is some evidence of a positive correlation between inequality and informality.

Problems related to omitted variables are also very relevant when trying to model the link between inequality and informality. Diverse social and economic interventions can influence both inequality and informality. This may be especially important in the Uruguayan case, as many changes in social and economic policies were in place simultaneously and may have affected both inequality and informality, as discussed in the next section.

\section{Policies and their role in the process of formalization}

The first relevant aspect to highlight is the macroeconomic context in which the formalization process took place. Uruguay was marked by economic growth during 
the last decade, with an average GDP growth of $5.7 \%$ between 2004 and 2013. While it is not necessarily the case that economic growth leads to a decrease in informality, as seen with the Uruguayan experience of the 1990s, it is important to recognize that economic growth and stability provide very favorable conditions for its reduction. In a context of economic stability, the risks of layoffs-and their associated costs in the case of formal workers-are lower, which can give employers an incentive to favor formality. Also, lower unemployment rates can increase workers' bargaining power and their chances of being formalized. Finally, the increase in demand for goods and services in periods of economic growth benefits the selfemployed and may increase earnings, which can contribute to covering the costs of formalization. All of these factors may have played a role in the recent evolution of informality in Uruguay, confirming the existing evidence on the pro-cyclical behavior of formal employment.

Another relevant aspect in the recent Uruguayan experience is the significant set of reforms and new policies that were implemented. They include the reinstatement of collective bargaining in 2005, the significant increase in minimum wages from December 2004, the tax reform implemented in 2007, the creation of the National Health System in 2008, and the inception of conditional cash transfers for families with children in 2006. In some cases, these policies may have had an impact on formalization, changing the incentives of firms and workers to operate in the formal or informal sector. In other cases, they may have influenced the wage differential between formal and informal sectors. Unfortunately, there are no evaluations to assess the impact of most of these policies on informality. Nevertheless, we cannot pretend that formalization came as an entirely exogenous change. As stated before, it may have been endogenous to economic growth or associated to changes in the institutional rules that drive the formal labor market. The main legal and institutional changes that affected the labor market are summarized in the Appendix.

\section{Methodology and data}

In this paper, we rely on the microeconometric decompositions proposed by Firpo et al. (2011) in order to compute the differential effects of several variables across the wage distribution and to disentangle the contribution of each variable. This method allows us to decompose the total change of a distributional statistic into a composition or characteristic effect, which captures the impact of the variations in the distribution of covariates $(X)$, and a wage structure or return effect, which reflects how the conditional distribution of wage $(F(w / x))$ changes in that period.

The first step consists in the estimation of recentered influence function regressions (RIF regressions), proposed by Firpo et al. (2007). These functions allow us to approximate non-linear functionals of the distribution, as a way to extend the traditional Oaxaca-Blinder decomposition of mean earnings to other features of the distribution. In this way, RIF regressions permit the decomposition of changes in wages at each quantile of the distribution separating the component attributable to a composition or to a price effect for each explanatory variable.

The influence function (IF) is used to build measures of robustness of a statistical $v(F)$ in the presence of outliers. Therefore, the IF is a function that captures the influence of an observation on $v(F)$. Its generic expression is given by: 
$F(Y ; v, F)=\lim _{\epsilon \rightarrow 0}\left(\frac{\nu\left(F_{\epsilon}\right)-v(F)}{\nu\left(F_{\epsilon}\right)}\right)$

where $F_{\epsilon}=(1-\epsilon) F+\epsilon \delta_{\mathrm{y}}$, with $0 \leq \epsilon \leq 1$

The parameter $\delta_{y}$ represents a distribution that only puts mass in the value $y$ of the $Y$ distribution. An important property of IF is $\int_{-\infty}^{\infty} \operatorname{IF}(y ; v) d F(y)=0$. The recentered influence function (RIF) is defined as $\operatorname{RIF}=v(F)+\operatorname{IF}(y ; v)$. Therefore, the RIF satisfies:

$$
\int_{-\infty}^{\infty} \operatorname{RIF}(y ; v) d F(y)=v(F)
$$

The instrumentation of a microeconometric decomposition based on RIF regression requires to compute two counterfactual statisticals:

$$
\begin{aligned}
& v_{t}^{C}=h_{g=t+n}^{v c}=E\left[\operatorname{RIF}\left(y_{t} ; v\right) / X, g=t+n\right] \\
& v_{t+n}^{C}=h_{g=t}^{v c}=E\left[\operatorname{RIF}\left(y_{t+n} ; v\right) / X, g=t\right]
\end{aligned}
$$

The functions $h$ may be non-linear. However, it is possible to generate a first-order local approximation based on linear regressions. From the model $h_{g}^{\text {lineal }}=x^{T} \gamma_{g}$, we can obtain the parameters $\left(\hat{\gamma}_{t}, \hat{\gamma}_{t+n}, \hat{\gamma}_{C, t}, \hat{\gamma}_{C, t+n}\right)$. The parameters $\hat{\gamma}_{t}$ and $\hat{\gamma}_{t+n}$ arise from the regression for each year. The counterfactual vector $\hat{\gamma}_{C, t}$ comes from a regression in year $t$, reweighted to match the $X$ distribution at $t+n$. Lastly, $\hat{\gamma}_{C, t+n}$ is computed by estimating a regression with the observations belonging to $t+n$ but using weights that correspond to the $X$ distribution at $t$.

Hence, the aggregate decomposition can be expressed as:

$$
\begin{aligned}
& \Delta_{s}^{v}=v_{t+n}-v_{t}^{C}=E[X / g=t+n]^{T}\left(\hat{\gamma}_{t+n}-\hat{\gamma}_{C, t}\right) \\
& \Delta_{X}^{v}=v_{t}^{C}-v_{t}=E[X / g=t+n]^{T} \hat{\gamma}_{C, t}-E[X / g=t]^{T} \hat{\gamma}_{t} \\
& \Delta_{O}^{v}=\Delta_{X}^{v}+\Delta_{S}^{v}
\end{aligned}
$$

where $\Delta_{s}^{v}$ and $\Delta_{X}^{v}$ are the wage structure effect and the composition effect, respectively.

If the function $h$ is non-linear, then $\hat{\gamma}_{t}$ and $\hat{\gamma}_{C, t}$ are not equal. In this case, the composition effect includes an error term $R^{v}$ :

$$
\begin{aligned}
& \Delta_{X}^{v}=v_{t}^{C}-v_{t}=\left(E[X / g=t+n]^{T}-E[X / g=t]^{T}\right) \hat{\gamma}_{t}+R^{v} \\
& \text { with } R^{v}=E[X / g=t+n]^{T}\left(\hat{\gamma}_{t}^{C}-\hat{\gamma}_{t}\right)
\end{aligned}
$$

$R^{v}$ is the lineal projection error. Its magnitude is a way to evaluate the goodness of fit of the linear approximation obtained through the RIF regressions (Firpo et al. 2007).

Finally, the detailed decomposition is computed as the contribution of each variable to the wage structure and composition effect, which allows us to isolate the specific effect of each variable: 


$$
\begin{aligned}
& \Delta_{X}^{v}=\sum_{k=1}^{K}\left(E\left[X_{k} / g=t+n\right]^{T}-E\left[X_{k} / g=t\right]^{T}\right) \hat{\gamma}_{t, k}+R^{v} \\
& \Delta_{S}^{v}=\sum_{k=1}^{K} E\left[X_{k} / g=t+n\right]^{T} \hat{\gamma}_{k, C, t}-E\left[X_{k} / g=t\right]^{T} \hat{\gamma}_{k, t}
\end{aligned}
$$

Our estimations are based on data from the Uruguayan household survey for the period 2001-2013. ${ }^{1}$ Informality, measured as the percentage of workers who do not make contributions to the social security system, is included as an explanatory variable. Other explanatory variables include sex, educational levels (five groups), age (three groups), marital status, geographical region, a binary variable for public employees, and controls for industry. The regressions and decomposition exercises detailed in the next section were conducted among employees from the private and public sectors aged 18 to 60 . We restrict our analysis to people aged 18 and above to obtain a sample with a more stable labor market participation, and only included people under 60 because this represents retirement age. This universe of salaried workers represents almost $75 \%$ of total employment.

\section{Results}

The presentation of our main results is organized into three parts. First, we present a counterfactual wage density decomposition as an illustration of the role of formality in distributional changes. Second, based on RIF regressions, we discuss aggregate decomposition of changes in inequality indicators, to evaluate the role of price and characteristic effects. Finally, we present results from detailed decompositions to illustrate the contribution of each variable within these effects. Given the dynamics of the Uruguayan labor market, the 2001-2013 period is disaggregated into two sub-periods: 2001-2006 and 2006-2013. In the first sub-period, characterized by the economic crisis and subsequent recovery, we observe a fall in real wages without major changes in the level of inequality, or even with a slight upward trend. The latter period of economic expansion occurs in a context of significant institutional and regulatory change, a strong process of formalization, and a fall in the level of wage inequality.

\subsection{Counterfactual density function}

Following the semi-parametric methodology proposed by DiNardo et al. (1996), we estimate the wage density in 2013 assuming that the degree of formalization is that prevailing in 2001, whereas other characteristics of employees remain unchanged. The difference between the counterfactual and actual density functions in 2013 reflects the variation in the distribution which can be attributed to the process of formalization. By comparing the counterfactual density and the actual density in 2013, we can see a shift in the lower part of the distribution to a little above the average that can be attributed to a formalization effect (Fig. 2). The biggest change is seen between the 10th and 50th percentiles, while the variations are smaller in the upper parts of the distribution.

These results are summarized in Table 1. Approximately $26 \%$ of the total decline in the Gini index (equivalent to one and a half points in the index) is related to changes in labor formalization. The effect is much more pronounced on the ratio between the 50th and 10th percentiles (p50/p10). In this case, formalization explains $125 \%$ of the variation in labor inequality. 

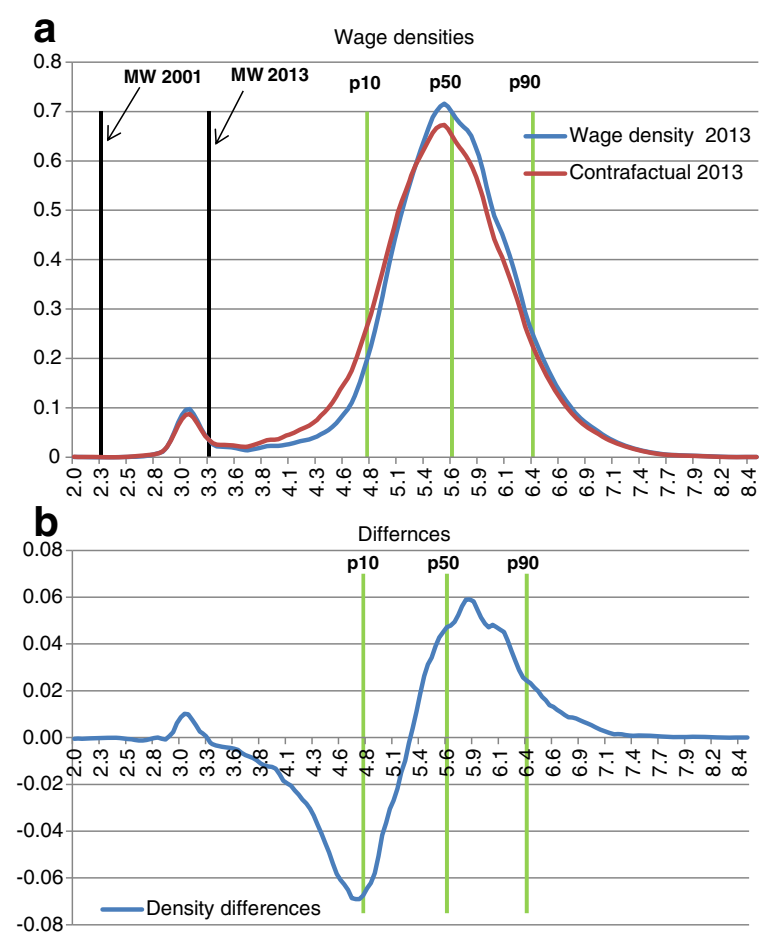

Fig. 2 a, b Impact of formalization on wage density, 2001-2013. Source: own estimations based on household surveys

These results provide a first hint about the potential equalizing role of formalization, the decomposition of changes in inequality presented below help to deepen our understanding of the underlying processes.

\subsection{RIF regressions and aggregate decomposition}

Results from RIF-based regressions show that the formality premium at the median of the distribution increases between 2001 and 2007, and then starts to decline until it reaches a minimum in $2013 .^{2}$ Additionally, the marginal effect of formalization decreases across the distribution and nearly becomes null at the top of it in all years. Returns to secondary and post-secondary education increase between 2001 and 2006, and then began to diminish. The gender gap is relatively stable across the period-changes are not statistically significant; the regional gap-favorable to Montevideo, the capital of the country-declines significantly at the median of the distribution and tends to disappear.

Table 1 Effect of formalization on hourly wages. Dinardo et al. (1996) decomposition

\begin{tabular}{lllllll}
\hline Statistic & 2001 & 2013 & 2013 (2001 formality) & Total change & Formality effect & \% formality in total effect \\
\hline $90-10$ & 1.798 & 1.538 & 1.684 & -0.259 & -0.145 & $56 \%$ \\
$90-50$ & 0.937 & 0.769 & 0.799 & -0.167 & -0.030 & $18 \%$ \\
$50-10$ & 0.861 & 0.769 & 0.884 & -0.092 & -0.115 & $125 \%$ \\
Gini & 0.410 & 0.351 & 0.366 & -0.059 & -0.015 & $26 \%$ \\
\hline
\end{tabular}

Source: own estimations based on household surveys 
A more detailed analysis by income percentile shows that wages grow along the entire distribution between 2001 and 2013, with a clear equalizing pattern: the rate of variation falls across the distribution (Fig. 3a). This differential evolution along the distribution is linked to a price effect, as the composition effect indicates a positive variation in remuneration which is relatively homogenous across the distribution. There are important differences across sub-periods. Between 2001 and 2006, the composition effect has a positive impact on wages, but the variation is dominated by a price effect, which leads to an overall decline in the level of wages-which is smaller in the upper part of the distribution (Fig. 3b). The combined effect is negative across the entire distribution and is also associated with a slight increase in inequality. Between 2006 and 2013, wage increases benefit those at the bottom of the income distribution, while the positive impact of the composition effect on wages is relatively homogenous across the distribution. Equalizing changes in the distribution are dominated by a price effect in this second sub-period (Fig. 3c).

The decomposition of the main inequality indicators confirms these results. The decrease in the Gini index during the whole period is dominated by the price effect (Table 2). The price-or returns-effect is the main driving factor in the upper part of the distribution (90-50), while the composition effect accounts for a larger share of the gap between the median and the lower tail of the distribution. Again, differential patterns are detected in both sub-periods. The slight increase in the Gini coefficient between 2001 and 2006 is the result of both a price and a composition effect, with relatively similar incidences along the distribution. The significant decrease in the Gini coefficient between 2006 and 2013 is mainly the effect of the price effect, although

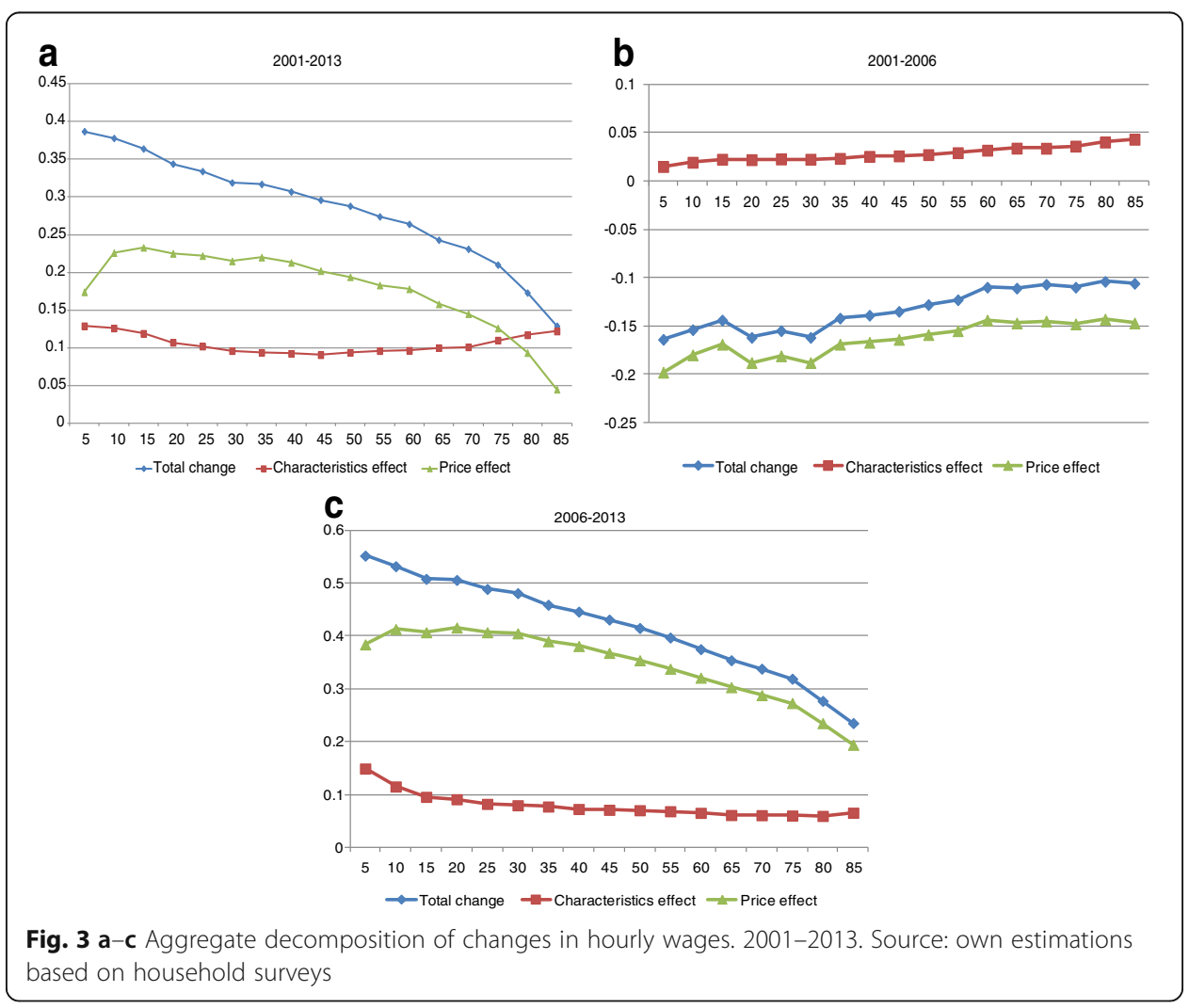


Table 2 Decomposition of the main indicators of inequality

\begin{tabular}{|c|c|c|c|c|c|c|c|c|c|c|c|c|}
\hline & \multicolumn{4}{|c|}{ 2001-2013 } & \multicolumn{4}{|c|}{ 2001-2006 } & \multicolumn{4}{|c|}{ 2006-2013 } \\
\hline & $90-10$ & $90-50$ & 50-10 & Gini & $90-10$ & $90-50$ & $50-10$ & Gini & $90-10$ & $90-50$ & $50-10$ & Gini \\
\hline \multirow[t]{2}{*}{ Total change } & -0.258 & -0.167 & -0.091 & -0.059 & 0.058 & 0.029 & 0.029 & 0.01 & -0.317 & -0.196 & -0.121 & -0.069 \\
\hline & {$[0.0205]$} & {$[0.0145]$} & {$[0.0147]$} & {$[0.00118]^{* * *}$} & {$[0.0214]$} & {$[0.0148]$} & [0.0164] & {$[0.00131]^{* * *}$} & {$[0.0116]$} & [0.0082] & {$[0.0085]$} & {$[0.00103]^{* * *}$} \\
\hline \multirow[t]{2}{*}{ Returns } & -0.129 & -0.157 & 0.028 & -0.062 & 0.051 & 0.017 & 0.034 & 0.007 & -0.19 & -0.174 & -0.016 & -0.063 \\
\hline & {$[0.0231]$} & [0.0143] & {$[0.0181]$} & {$[0.000336]^{* * *}$} & {$[0.0207]$} & {$[0.0141]$} & {$[0.0162]$} & {$[0.000213]^{* * *}$} & {$[0.0122]$} & {$[0.0079]$} & {$[0.0096]$} & {$[0.000222]^{* * *}$} \\
\hline \multirow[t]{2}{*}{ Composition } & -0.007 & 0.031 & -0.038 & -0.01 & 0.028 & 0.017 & 0.011 & 0.006 & -0.084 & -0.006 & -0.078 & -0.013 \\
\hline & {$[0.0135]$} & [0.0096] & [0.0091] & {$[0.00114]^{* * *}$} & {$[0.0073]$} & [0.0058] & [0.0040] & {$[0.00133]^{* * *}$} & {$[0.0064]$} & {$[0.0037]$} & {$[0.0047]$} & {$[0.000985]^{* * *}$} \\
\hline \multirow[t]{2}{*}{ Interaction } & -0.122 & -0.041 & -0.081 & 0.013 & -0.022 & -0.006 & -0.016 & -0.002 & -0.043 & -0.016 & -0.026 & 0.007 \\
\hline & {$[0.0158]$} & {$[0.0095]$} & {$[0.0134]$} & {$[0.000622]^{* * *}$} & {$[0.0060]$} & [0.0042] & [0.0043] & {$[0.000255]^{* * *}$} & {$[0.0070]$} & {$[0.0034]$} & {$[0.0062]$} & {$[0.000303]^{* * *}$} \\
\hline Total & $100 \%$ & $100 \%$ & $100 \%$ & $100 \%$ & $100 \%$ & $100 \%$ & $100 \%$ & $100 \%$ & $100 \%$ & $100 \%$ & $100 \%$ & $100 \%$ \\
\hline Returns & $50 \%$ & $94 \%$ & $-31 \%$ & $105 \%$ & $88 \%$ & $59 \%$ & $117 \%$ & $70 \%$ & $60 \%$ & $89 \%$ & $13 \%$ & $91 \%$ \\
\hline Composition & $3 \%$ & $-19 \%$ & $42 \%$ & $17 \%$ & $48 \%$ & $59 \%$ & $38 \%$ & $60 \%$ & $26 \%$ & $3 \%$ & $64 \%$ & $19 \%$ \\
\hline Interaction & $47 \%$ & $25 \%$ & $89 \%$ & $-22 \%$ & $-38 \%$ & $-21 \%$ & $-55 \%$ & $-20 \%$ & $14 \%$ & $8 \%$ & $21 \%$ & $-10 \%$ \\
\hline
\end{tabular}

Source: own estimations based on household surveys

***Significant at $1 \%$ 
different patterns are evident across the distribution. The composition effect prevails in the lower part of the distribution, whereas the price effect explains most of the decline in inequality between the median and the 90th percentile. A detailed decomposition is needed in order to understand what factors are behind these aggregate price and composition effects.

\subsection{Detailed decomposition}

In order to illustrate the main results of the detailed decomposition, the relative importance of each factor along the percentiles of the distribution is presented in Figs. 4 and 5 (composition and return effects, respectively). Given the importance of education and informality, these factors are presented in a separate figure. For the whole period, the relative low relevance of the aggregate composition effect is explained by the opposite effect of the changes in educational attainment and the employment distribution between the formal and informal sectors: whereas the first factor shows an increasing curve, the second shows a decreasing pattern (Fig. 4). On the other hand, the returns to education and the wage differential between the formal and informal sectors have a clear equalizing effect (Fig. 5)

As a result, a first in-depth analysis of the composition effect reveals an interesting pattern. The relative homogeneity and moderate magnitude of the composition effect discussed in the previous section are the result of the diverging impacts of formalization and the evolution of workers' educational levels (Fig. 4a), which tend to counterbalance. Whereas the increase in the supply of educated workers has been inequality increasing, the increase in the number of formal workers has acted in the opposite direction, pushing for a decline in labor income inequality during the whole period. The other variables have minor composition effects over the whole distribution of wages (see Fig. 4b).

As mentioned, both formality and education have reinforcing price effects, which lead to an equalizing result (Fig. 5). Changes in formality premium mainly positively impact the lower end of the distribution. As for returns to education, they also have a positive effect on wages in the lower percentiles, although the magnitude is smaller than that of formality prices, but the effect becomes negative above the median (see Fig. 5a). Two additional variables exhibit a significant price or return effect: the gap between Montevideo and the interior and wage differences by industry (see Fig. 5b). Both of these factors partially compensate the equalizing price effects of education and formality. The aggregate effect of industry is reflecting changes in wage differentials by activity sector that also account for the evolution of inequality. ${ }^{3}$
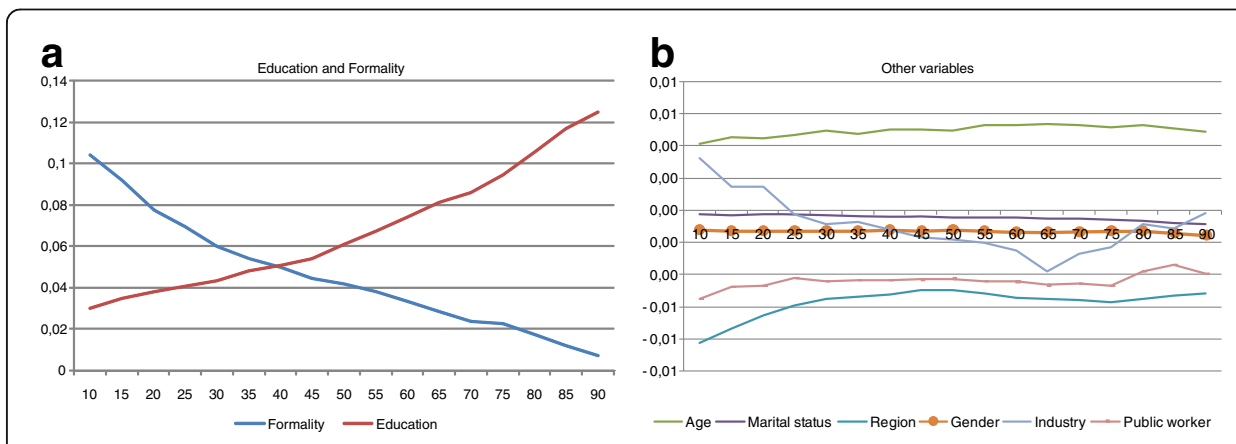

Fig. 4 a, b Detailed composition effect. 2001-2013. Source: own estimations based on household surveys 

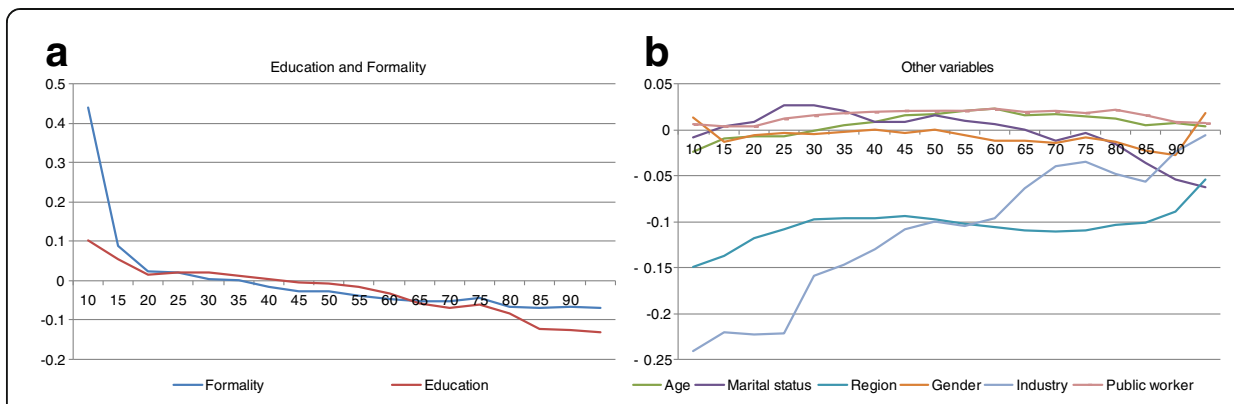

Fig. 5 a, b Detailed price effect. 2001-2013. Source: own estimations based on household surveys

The analysis by sub-period indicates that, in the case of the composition effect, there is a clear link between formalization and inequality dynamics between 2006 and 2013, while the increase in education levels exhibits a concentrating pattern in both sub-periods. Notably, the effect of the wage premium on formality has a positive impact on inequality in both periods, and the same happened with returns to education (Table 3).

One of the advantages of RIF regressions is that they allow us to calculate the unconditional marginal effect of an explanatory variable on wages along the distribution or on different distributive statistics. Figure 6 shows the marginal impact of formalization by percentile, indicating why the process of formalization, ceteris paribus, triggers a reduction in wage inequality. For the 3 years considered, the marginal effect varies negatively and monotonically with the percentile, becoming almost null in the upper tail of the distribution. Given this pattern of the formality premium across the

Table 3 Decomposition of the main inequality indicators. Role of formalization and education

\begin{tabular}{lllll}
\hline & $90-10$ & $90-50$ & $50-10$ & Gini \\
\hline 2001-2013 & & & -0.011 & -0.072 \\
Total change & -0.137 & -0.126 & -0.532 & -0.054 \\
Formality & -0.605 & -0.073 & -0.082 & -0.035 \\
Education & -0.137 & -0.056 & 0.260 & 0.007 \\
Other & 0.226 & -0.034 & 0.344 & 0.010 \\
Interaction & 0.380 & 0.036 & & \\
2001-2006 & & & 0.045 & 0.012 \\
Total change & 0.079 & 0.035 & -0.260 & -0.015 \\
Formality & -0.327 & -0.067 & -0.063 & -0.010 \\
Education & -0.097 & -0.035 & 0.369 & 0.013 \\
Other & 0.318 & -0.051 & -0.002 & 0.024 \\
Interaction & 0.185 & 0.187 & & \\
2006-2013 & & & -0.094 & -0.076 \\
Total change & -0.274 & -0.180 & -0.309 & -0.037 \\
Formality & -0.322 & -0.013 & -0.023 & -0.018 \\
Education & -0.062 & -0.039 & -0.108 & -0.006 \\
Other & -0.085 & 0.024 & 0.346 & -0.015 \\
Interaction & 0.194 & -0.152 & & \\
\hline
\end{tabular}

Source: own estimations based on household surveys 


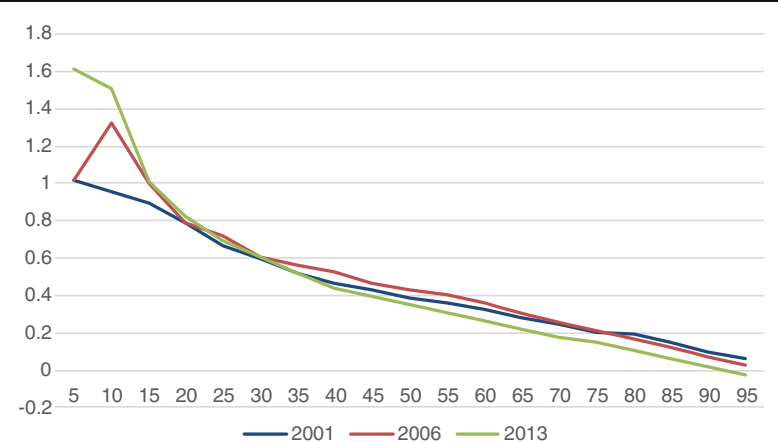

Fig. 6 Marginal effect of formality by percentile. Source: own estimations based on household surveys

distribution, an increase in formalization unequivocally leads to a reduction in inequality: the income of all percentiles tends to increase, but the effect is larger at lower percentiles. This result can be measured through the composition effect: if the marginal effects are held constant relative to the base year, the change in the degree of formalization reduces inequality.

The other relevant variable to understand the evolution of inequality is education. Figure 7 shows the marginal effect of the binary variables used for each level of education, the reference group being the least educated-less than 6 years of formal education. As expected, the marginal effect for all educational groups increases with the percentile, but this pattern becomes clearer for higher levels of education. This feature can be observed for the 3 years considered. Second, the composition

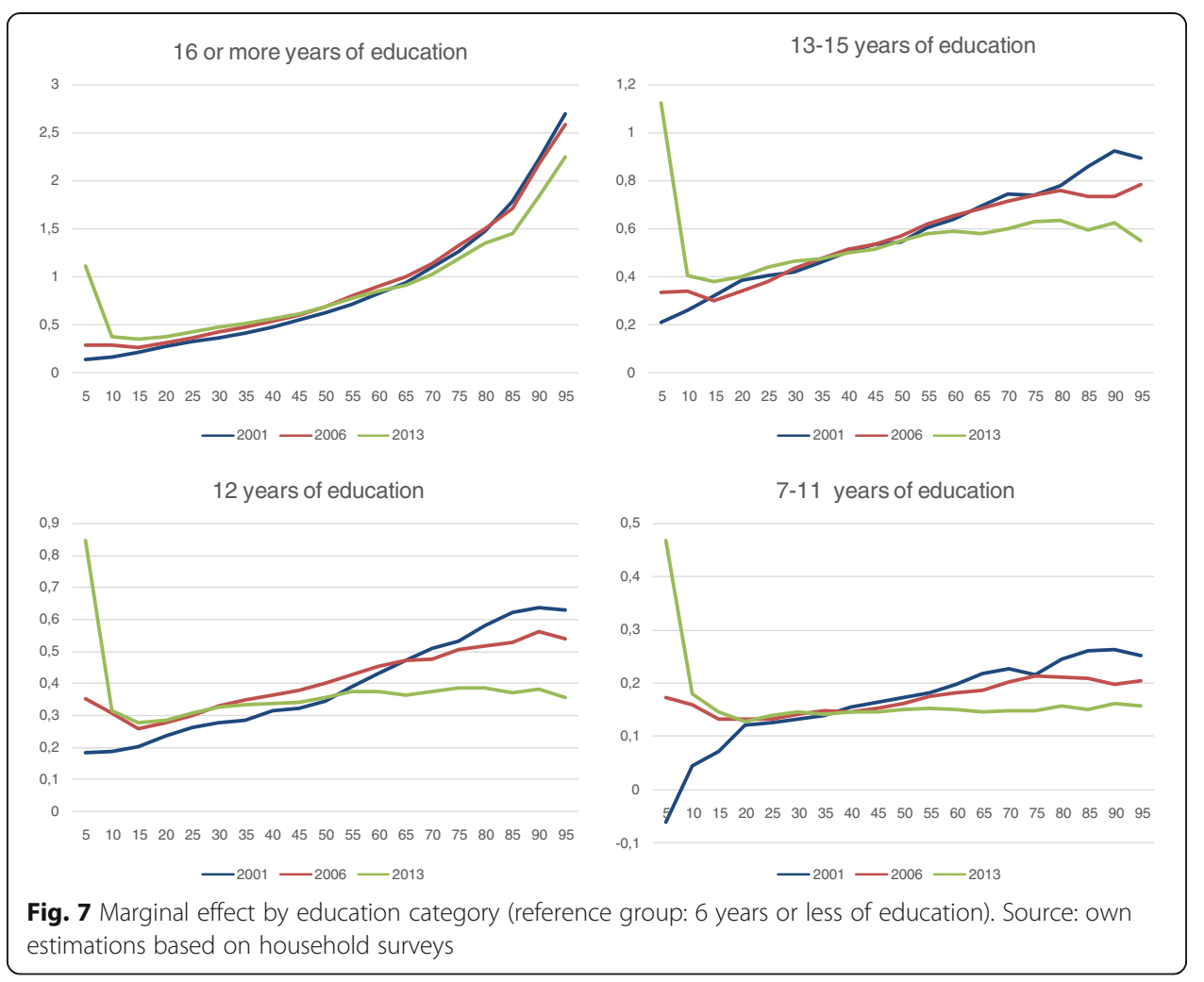


effect of education has a negative impact on inequality indices. An increase in the participation of the most educated groups causes a non-uniform increase throughout the wage distribution, and the absolute value of the change increases with the percentile.

However, changes in the marginal effect patterns explain why the price effect of education has a positive impact on inequality. The slope of the curves tapers off between 2001 and 2013. Thus, the wage differences by education level alleviate the impact on inequality during the period.

In sum, inequality decline is mainly driven by the overall progressive impact of the price effect, which in turn is dominated by informality and education. The aggregate composition effect is neutralized by the opposite effects of the increase in workers' education level (unequalizing) and the increase in the number of formal workers (equalizing).

The importance of the process of formalization in explaining the recent evolution of wage inequality is evident when jointly considering the composition and return effects of these variables. The incidence of formalization on wage inequality dynamics via both channels-changes in the wage premium and increase in the number of formal workers-is summarized in Fig. 8, and compared with that of education and other factors. The bars represent the sum of the price and composition effects of formality, education, and other factors. This aggregate impact is very large below the 20th percentile in the case of formality and becomes lower for the rest of the distribution. The overall change induced by formalization in these first percentiles far exceeds the total observed variation, and other factors acted to cushion the change induced by the increase in social security coverage among employed workers.

Our main results are summarized in Table 3. The impact of formalization-both trough prices and composition effect-accounts for a significant share of the total change in inequality indices. This is particularly striking when it comes to indices relative to the 10th percentile-the 90-10 and 50-10 differentials-where the impact of formality is higher and is more evident between 2006 and $2013 .^{4}$

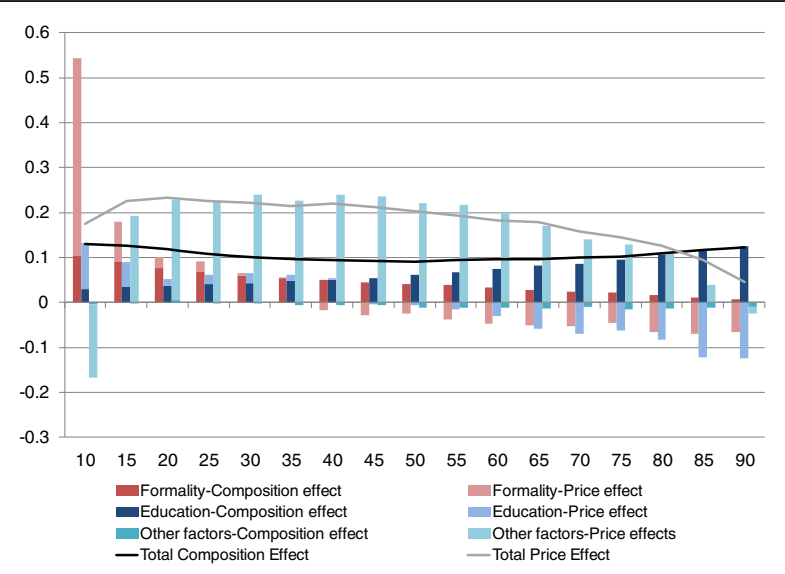

Fig. 8 Effect of formalization on the evolution of inequality. 2001-2013. Source: own estimations based on household surveys 
Most of the changes in the synthetic indexes, like the Gini coefficient and the ratios $90-10$ and 90-50, are due to return effects, which in turn are dominated by the incidence of formality and education, both with inequality-reducing effects (see Table 3). Results are different for the ratio 50-10, an index which reflects movements in the lower part of the distribution. Those movements are clearly governed by the composition effect and specifically by the increase in the number of formal workers in the lower part of the distribution, which had a significant equalizing effect. The increase in the number of formal workers clearly favors the lower percentiles of the distribution, while changes in educational attainment lead to higher changes in remuneration in the upper segments.

Given the importance of the two aforementioned factors, it is necessary to consider plausible hypotheses to explain these dynamics. Regarding the evolution of returns to education, its decline has had a positive impact on inequality during this period. Four possible factors may explain this decline: (1) the tax reform, (2) the increase in minimum wages, (3) collective bargaining, and (4) the changes in labor demand by education level, induced by the recent economic boom. The tax reform reduced the wage gaps in terms of net income and this impact was relatively linear: the net income of highly educated workers was reduced after the tax reform, while that of low-educated workers increased. The introduction of minimum wage and collective wage bargaining can also account for part of the inequality reduction; it had a positive impact on formal workers' income, either by affecting the minimum threshold-minimum wage-or by compressing the distribution of wages by sector-collective bargaining. The potential role of changes in the relative demand for qualified workers is less clear. There was a significant increase in labor demand overall-with the lowest unemployment levels recorded over the last four decades-but no systematic study has identified differential variation in labor demand in Uruguay. The economic dynamism of sectors relying intensively on unskilled labor-e.g., agriculture, mining-can partially account for the reduction in returns to education, because of the increase in the relative demand for unskilled workers, as suggested by the analysis of other countries in the region (Gasparini et al. 2012). Moreover, the increase in the formality premium in the first percentiles of the income distribution may also be related to both minimum wages and wage bargaining, although this remains an open research question. ${ }^{5}$ In any case, our results indicate that changes in the institutional characteristics that regulate the allocation of the workers between the formal and informal sectors and the different rules of wage formation in both sectors cannot be ignored in order to understand the dynamics of inequality in the context of the developing economies.

\section{Conclusions}

Since 2004, the Uruguayan labor market has experienced a process of formalization-understood as an increase in the number of employees who contribute to social security, and the related change in the premium for formality. On the other hand, from 2007 on, all inequality indicators exhibited a significant decrease. This article attempted to link these phenomena using microeconometric decompositions to understand wage inequality dynamics. 
The aggregated decomposition indicates that the decline in inequality between 2001 and 2013 is mainly explained by the return effect, with the composition effect reflecting a positive variation in wages which was homogeneous across the distribution. The detailed decomposition indicates that the most significant effects, in terms of magnitude, are the ones related to formalization and education. The relative homogeneity of the composition effect at the aggregate level is the result of two processes with opposite effects that tend to neutralize each other. The increase in the quantity of formal workers induces an increase in wages in the lower percentiles of the distribution-contributing to lower inequality-while the increase in workers' educational attainment leads to higher wages in the upper part of the distribution, with an unequalizing effect. These two effects tend to cancel out and result in a non-relevant composition effect at the aggregate level.

Regarding returns, both formalization and the level of education have equalizing effects. The change in the formality premium has an upward impact on wages at the bottom of the distribution. As for returns to education, they have a positive impact on wages at the bottom of the distribution, but the effect becomes negative in the higher part.

Unlike most of the previous literature, our results highlight the importance of the formalization process that took place in the Uruguayan labor market as a key factor in understanding the decrease in earning inequality over the period being analyzed. While informality cannot be claimed to be exogenous, its effect should be interpreted as reflecting that of labor market institutions. The regulatory framework within which labor relations develop in the formal economy-e.g., mechanisms to determine wages, regulations of minimum wages, social security benefits, etc.-highly determines the degree of wage inequality in the Uruguayan labor market.

\section{Endnotes}

${ }^{1}$ In order to maintain consistency in the time series, only urban areas with at least 5000 inhabitants are considered-i.e. we exclude rural areas and smaller urban areas that only appear in the household surveys starting in 2006. This sample accounts for around $85 \%$ of the total population of Uruguay. The analysis of informality is conducted as of 2001, which corresponds to the first year in which the survey asks a specific question about contributions to social security.

${ }^{2}$ Results from the RIF regressions estimations are available under request. Summary statistics from our data are included in Table 6

${ }^{3}$ The excluded variable is the agriculture and mining sector.

${ }^{4}$ Detailed decompositions of main inequality indexes for the whole period and for sub-periods are included in Tables 7, 8, and 9.

${ }^{5}$ The general equilibrium effects of these changes are not clear. In particular, they could trigger "spillover" effects in the informal sector, to the extent that the national minimum wage or specific minimum wage of a category could serve as a signal in the process of wage determination in informal conditions. 


\section{Appendix}

\section{Main policies and institutional changes that affected the Uruguayan labor market}

\begin{tabular}{ll}
\hline Policies & Possible impact \\
Mandatory collective & $\begin{array}{l}\text { Since } 2006 \text { wages have been set in the framework of mandatory collective bargaining. } \\
\text { bargaining }\end{array}$ \\
& $\begin{array}{l}\text { This institution was not operating since 1992. Tripartite negotiations about wage levels } \\
\text { and changes were set at the sector level, with the participation of representatives of } \\
\text { employers, workers and the government, and basically covered all formal workers in } \\
\text { the economy. These changes affect wage formation in the formal sector. }\end{array}$
\end{tabular}

Minimum wage

By the beginning of the twenty-first century the minimum wage had completely lost its role as a reference price in the labor market. This was the result of a strategy to avoid deteriorating public accounts, as various public social benefits were indexed to the minimum wage. In 2004, a law was passed to finish that indexation, and the minimum wage started to increase significantly.

Tax reform

A tax reform was implemented in 2007, including the granting of tax incentives - through the reduction of corporate income taxes-for productive investment with formal job creation. An impact evaluation of these interventions revealed that the promotion of investment was associated with an increase-between 10 and $35 \%$ depending on the estimation_in formal employment (Llambí et al. 2014). In turn, the reform included changes in the marginal income taxes, generating a more progressive tax system.

National Health System The creation of the National Health System in 2008 extended health coverage to the family of formal workers - an extension that was financed by increasing the social contribution for health insurance. An impact evaluation of this reform finds that the share of individuals with registered employment increased by 1.6 percentage points, which represents a $5 \%$ increase in formal employment (see Bérgolo and Cruces 2014).

Conditional cash transfer programs

Conditional cash transfer programs may alter the incentives to engage in the formal sector. In order to be eligible and remain in the program, individuals had to receive an income below a given threshold-and this income was computed as the formal income reported in social security records. For instance, Amarante et al. (2011) find that PANES, a non-contributory transfer program targeting Uruguayan households with children in 2006 and 2007, reduced male formality and labor income. Similarly, Bérgolo and Cruces (2014) find that the new Family Allowance program, a noncontributory transfer of the same nature as PANES and implemented in 2008 , decreased formal employment for adults in eligible households by between 18 and $30 \%$.

Table 4 Informality by occupational category

\begin{tabular}{|c|c|c|c|c|c|c|c|}
\hline & Specific & & & & Distribu & & \\
\hline & $\begin{array}{l}\text { Private } \\
\text { salaried } \\
\text { (1) }\end{array}$ & $\begin{array}{l}\text { Self-employed } \\
\text { without } \\
\text { premises }\end{array}$ & $\begin{array}{l}\text { Self-employed } \\
\text { with premises }\end{array}$ & $\begin{array}{l}\text { Domestic } \\
\text { services } \\
\text { (included in 1) }\end{array}$ & $\begin{array}{l}\text { Private } \\
\text { salaried } \\
\text { (1) }\end{array}$ & $\begin{array}{l}\text { Self-employed } \\
\text { without } \\
\text { premises }\end{array}$ & $\begin{array}{l}\text { Self- } \\
\text { employed } \\
\text { with } \\
\text { premises }\end{array}$ \\
\hline 2002 & $31 \%$ & $91 \%$ & $65 \%$ & $69 \%$ & $44 \%$ & $25 \%$ & $25 \%$ \\
\hline 2004 & $36 \%$ & $94 \%$ & $69 \%$ & $73 \%$ & $47 \%$ & $21 \%$ & $26 \%$ \\
\hline 2006 & $28 \%$ & $94 \%$ & $70 \%$ & $59 \%$ & $44 \%$ & $18 \%$ & $32 \%$ \\
\hline 2008 & $25 \%$ & $96 \%$ & $70 \%$ & $55 \%$ & $43 \%$ & $12 \%$ & $38 \%$ \\
\hline 2010 & $23 \%$ & $97 \%$ & $70 \%$ & $53 \%$ & $43 \%$ & $10 \%$ & $42 \%$ \\
\hline 2012 & $17 \%$ & $95 \%$ & $67 \%$ & $53 \%$ & $39 \%$ & $10 \%$ & $45 \%$ \\
\hline 2013 & $15 \%$ & $97 \%$ & $66 \%$ & $50 \%$ & $37 \%$ & $9 \%$ & $48 \%$ \\
\hline
\end{tabular}

Source: own estimations based on household surveys 
Table 5 Wage inequality. 2000-2013

\begin{tabular}{|c|c|c|c|c|c|c|c|c|}
\hline & 2000 & 2002 & 2004 & 2006 & 2008 & 2010 & 2012 & 2013 \\
\hline Gini & 0.401 & 0.412 & 0.416 & 0.423 & 0.401 & 0.39 & 0.356 & 0.351 \\
\hline Theil & 0.295 & 0.313 & 0.32 & 0.332 & 0.294 & 0.272 & 0.223 & 0.22 \\
\hline
\end{tabular}

Source: own estimations based on household survey

Table 6 Summary of variables included in the decomposition of main inequality indexes. 2001, 2006, and 2013

\begin{tabular}{|c|c|c|c|}
\hline & 2001 & 2006 & 2013 \\
\hline \multicolumn{4}{|l|}{ Means } \\
\hline Informality (total labor force) & $31.4 \%$ & $28.1 \%$ & $15.0 \%$ \\
\hline Male participation in labor force & $56.8 \%$ & $55.3 \%$ & $54.5 \%$ \\
\hline Regional distribution of labor force (\% in Montevideo) & $53.1 \%$ & $49.4 \%$ & $49.8 \%$ \\
\hline \multicolumn{4}{|l|}{ Educational attainment } \\
\hline Primary complete or incomplete & $29.0 \%$ & $25.5 \%$ & $19.7 \%$ \\
\hline Secondary incomplete & $31.6 \%$ & $32.3 \%$ & $34.4 \%$ \\
\hline Secondary complete & $21.3 \%$ & $21.3 \%$ & $21.2 \%$ \\
\hline Post-secondary incomplete & $7.4 \%$ & $11.6 \%$ & $12.2 \%$ \\
\hline Post-secondary complete & $10.7 \%$ & $9.4 \%$ & $13.0 \%$ \\
\hline \multicolumn{4}{|l|}{ Age } \\
\hline Between 13 and 17 & $1.7 \%$ & $1.6 \%$ & $1.0 \%$ \\
\hline Between 18 and 24 & $13.7 \%$ & $12.0 \%$ & $12.7 \%$ \\
\hline Between 25 and 34 & $22.6 \%$ & $23.2 \%$ & $24.5 \%$ \\
\hline Between 35 and 44 & $24.5 \%$ & $23.1 \%$ & $23.8 \%$ \\
\hline Between 45 and 60 & $30.3 \%$ & $32.0 \%$ & $30.2 \%$ \\
\hline More than 60 & $7.2 \%$ & $8.0 \%$ & $7.8 \%$ \\
\hline Public employee & $16.6 \%$ & $16.5 \%$ & $15.5 \%$ \\
\hline \multicolumn{4}{|l|}{ Sector activity } \\
\hline Livestock, agriculture, and mining & $4.3 \%$ & $4.9 \%$ & $4.1 \%$ \\
\hline Manufacturing industry & $14.5 \%$ & $14.4 \%$ & $12.5 \%$ \\
\hline Electricity, gas, and water & $1.0 \%$ & $1.1 \%$ & $1.3 \%$ \\
\hline Construction & $8.1 \%$ & $6.6 \%$ & $8.2 \%$ \\
\hline Shops, restaurants, and hotels & $22.4 \%$ & $23.4 \%$ & $22.5 \%$ \\
\hline Transport and communications & $6.2 \%$ & $5.7 \%$ & $7.4 \%$ \\
\hline Business services & $9.0 \%$ & $8.0 \%$ & $10.0 \%$ \\
\hline Community, personal, and social services & $34.5 \%$ & $36.0 \%$ & $34.0 \%$ \\
\hline
\end{tabular}

Source: own estimations based on household surveys 
Table 7 Detailed decomposition of main inequality indexes. 2001-2013

\begin{tabular}{lllllllll}
\hline & $90-10$ & $90-50$ & $50-10$ & Gini & $90-10$ & $90-50$ & $50-10$ & Gini \\
\hline Detailed return effects & & & & & & & & \\
Formality & -0.506 & -0.040 & -0.466 & -0.035 & $392 \%$ & $26 \%$ & $-1664 \%$ & $56 \%$ \\
Education & -0.228 & -0.119 & -0.109 & -0.043 & $176 \%$ & $76 \%$ & $-390 \%$ & $69 \%$ \\
Age & 0.031 & -0.010 & 0.041 & 0.002 & $-24 \%$ & $6 \%$ & $146 \%$ & $-4 \%$ \\
Occupational category & 0.002 & -0.012 & 0.014 & -0.002 & $-2 \%$ & $8 \%$ & $50 \%$ & $3 \%$ \\
Industry & 0.217 & 0.076 & 0.141 & 0.017 & $-168 \%$ & $-48 \%$ & $505 \%$ & $-28 \%$ \\
Marital status & -0.045 & -0.069 & 0.024 & -0.013 & $35 \%$ & $44 \%$ & $86 \%$ & $21 \%$ \\
Sex & -0.041 & -0.028 & -0.013 & -0.006 & $32 \%$ & $18 \%$ & $-47 \%$ & $9 \%$ \\
Region & 0.061 & 0.009 & 0.052 & 0.007 & $-47 \%$ & $-5 \%$ & $186 \%$ & $-12 \%$ \\
Constant & 0.380 & 0.036 & 0.344 & 0.010 & $-294 \%$ & $-23 \%$ & $1228 \%$ & $-15 \%$ \\
Total return effect & -0.129 & -0.157 & 0.028 & -0.062 & $100 \%$ & $100 \%$ & $100 \%$ & $100 \%$ \\
Detailed composition effects $\%$ & & & & & & & & \\
Formality & -0.099 & -0.03 & -0.067 & -0.019 & $1420 \%$ & $-104 \%$ & $173 \%$ & $187 \%$ \\
Education & 0.091 & 0.063 & 0.028 & 0.008 & $-1294 \%$ & $201 \%$ & $-72 \%$ & $-75 \%$ \\
Age & 0.001 & 0.000 & 0.001 & 0.000 & $-17 \%$ & $0 \%$ & $-3 \%$ & $2 \%$ \\
Occupational category & 0.002 & 0.000 & 0.001 & 0.001 & $-22 \%$ & $1 \%$ & $-3 \%$ & $-14 \%$ \\
Industry & -0.003 & 0.002 & -0.005 & 0.000 & $50 \%$ & $5 \%$ & $13 \%$ & $0 \%$ \\
Marital status & 0.000 & 0.000 & 0.000 & 0.000 & $7 \%$ & $-1 \%$ & $0 \%$ & $0 \%$ \\
Sex & 0.000 & 0.000 & 0.000 & 0.000 & $5 \%$ & $-1 \%$ & $0 \%$ & $1 \%$ \\
Region & 0.003 & 0.000 & 0.003 & 0.000 & $-43 \%$ & $-1 \%$ & $-8 \%$ & $-1 \%$ \\
Total composition effect & -0.007 & 0.031 & -0.038 & -0.010 & $104 \%$ & $100 \%$ & $101 \%$ & $100 \%$ \\
\hline Soure: own $\%$ & \\
\hline
\end{tabular}

Source: own estimations based on household surveys

Table 8 Detailed decomposition of main inequality indexes. 2001-2006

\begin{tabular}{|c|c|c|c|c|c|c|c|c|}
\hline & $90-10$ & $90-50$ & $50-10$ & Gini & $90-10$ & $90-50$ & $50-10$ & Gini \\
\hline \multicolumn{9}{|l|}{ Detailed return effects } \\
\hline Formality & -0.310 & -0.062 & -0.249 & -0.012 & $-392 \%$ & $-180 \%$ & $-552 \%$ & $-97 \%$ \\
\hline Education & -0.141 & -0.065 & -0.076 & -0.019 & $-178 \%$ & $-189 \%$ & $-170 \%$ & $-149 \%$ \\
\hline Age & 0.022 & -0.011 & 0.033 & -0.002 & $28 \%$ & $-32 \%$ & $74 \%$ & $-18 \%$ \\
\hline Occupational category & 0.022 & -0.010 & 0.032 & -0.003 & $27 \%$ & $-30 \%$ & $71 \%$ & $-24 \%$ \\
\hline Industry & 0.267 & -0.007 & 0.274 & 0.009 & $337 \%$ & $-19 \%$ & $608 \%$ & $75 \%$ \\
\hline Marital status & -0.023 & -0.053 & 0.029 & -0.004 & $-29 \%$ & $-154 \%$ & $65 \%$ & $-29 \%$ \\
\hline Sex & 0.004 & 0.023 & -0.019 & 0.007 & $4 \%$ & $66 \%$ & $-43 \%$ & $59 \%$ \\
\hline Region & 0.026 & 0.014 & 0.012 & 0.006 & $33 \%$ & $41 \%$ & $26 \%$ & $45 \%$ \\
\hline Constant & 0.185 & 0.187 & -0.002 & 0.024 & $234 \%$ & $548 \%$ & $-4 \%$ & $193 \%$ \\
\hline Total return effect & 0.051 & 0.017 & 0.034 & 0.007 & $64 \%$ & $50 \%$ & $76 \%$ & $56 \%$ \\
\hline \multicolumn{9}{|l|}{ Detailed composition effects } \\
\hline Formality & -0.017 & -0.005 & -0.011 & -0.002 & $-21 \%$ & $-16 \%$ & $-25 \%$ & $-20 \%$ \\
\hline Education & 0.044 & 0.030 & 0.014 & 0.009 & $55 \%$ & $88 \%$ & $31 \%$ & $69 \%$ \\
\hline Age & 0.006 & 0.004 & 0.002 & 0.001 & $8 \%$ & $12 \%$ & $5 \%$ & $11 \%$ \\
\hline Occupational category & 0.000 & 0.000 & 0.000 & 0.000 & $0 \%$ & $0 \%$ & $0 \%$ & $1 \%$ \\
\hline Industry & -0.009 & -0.010 & 0.001 & -0.002 & $-11 \%$ & $-30 \%$ & $2 \%$ & $-19 \%$ \\
\hline Marital status & -0.001 & -0.001 & 0.000 & 0.000 & $-1 \%$ & $-2 \%$ & $0 \%$ & $-1 \%$ \\
\hline Sex & 0.000 & 0.000 & 0.000 & 0.000 & $0 \%$ & $-1 \%$ & $0 \%$ & $-1 \%$ \\
\hline Region & 0.005 & 0.000 & 0.005 & 0.001 & $6 \%$ & $-1 \%$ & $11 \%$ & $5 \%$ \\
\hline Total composition effect & 0.028 & 0.017 & 0.011 & 0.006 & $36 \%$ & $50 \%$ & $24 \%$ & $44 \%$ \\
\hline Total change & 0.079 & 0.034 & 0.045 & 0.013 & $100 \%$ & $100 \%$ & $100 \%$ & $100 \%$ \\
\hline
\end{tabular}

Source: own estimations based on household surveys 
Table 9 Detailed decomposition of main inequality indexes. 2006-2013

\begin{tabular}{lllllllll}
\hline & $90-10$ & $90-50$ & $50-10$ & Gini & $90-10$ & $90-50$ & $50-10$ & Gini \\
\hline Detailed return effects & & & & & & & & \\
Formality & -0.201 & 0.022 & -0.223 & -0.021 & $73 \%$ & $-12 \%$ & $237 \%$ & $28 \%$ \\
Education & -0.096 & -0.060 & -0.036 & -0.021 & $35 \%$ & $34 \%$ & $38 \%$ & $27 \%$ \\
Age & 0.009 & 0.001 & 0.007 & 0.005 & $-3 \%$ & $-1 \%$ & $-8 \%$ & $-6 \%$ \\
Occupational category & -0.019 & -0.002 & -0.018 & 0.001 & $7 \%$ & $1 \%$ & $19 \%$ & $-1 \%$ \\
Industry & -0.044 & 0.088 & -0.131 & 0.008 & $16 \%$ & $-49 \%$ & $139 \%$ & $-10 \%$ \\
Marital status & -0.022 & -0.017 & -0.005 & -0.010 & $8 \%$ & $9 \%$ & $5 \%$ & $13 \%$ \\
Sex & -0.044 & -0.050 & 0.006 & -0.013 & $16 \%$ & $28 \%$ & $-6 \%$ & $17 \%$ \\
Region & 0.033 & -0.005 & 0.038 & 0.002 & $-12 \%$ & $3 \%$ & $-40 \%$ & $-2 \%$ \\
Constant & 0.194 & -0.152 & 0.346 & -0.015 & $-71 \%$ & $85 \%$ & $-368 \%$ & $19 \%$ \\
Total return effect & -0.190 & -0.174 & -0.016 & -0.063 & $69 \%$ & $97 \%$ & $17 \%$ & $83 \%$ \\
Detailed composition effects $\%$ & & & & & & & & \\
Formality & -0.121 & -0.035 & -0.086 & -0.016 & $44 \%$ & $19 \%$ & $91 \%$ & $21 \%$ \\
Education & 0.035 & 0.021 & 0.013 & 0.002 & $-13 \%$ & $-12 \%$ & $-14 \%$ & $-3 \%$ \\
Age & -0.004 & -0.003 & -0.001 & -0.001 & $2 \%$ & $2 \%$ & $1 \%$ & $1 \%$ \\
Occupational category & -0.001 & 0.002 & -0.003 & 0.001 & $0 \%$ & $-1 \%$ & $3 \%$ & $-2 \%$ \\
Industry & 0.009 & 0.009 & 0.000 & 0.001 & $-3 \%$ & $-5 \%$ & $0 \%$ & $-1 \%$ \\
Marital status & 0.000 & 0.000 & 0.000 & 0.000 & $0 \%$ & $0 \%$ & $0 \%$ & $0 \%$ \\
Sex & 0.000 & 0.000 & 0.000 & 0.000 & $0 \%$ & $0 \%$ & $0 \%$ & $0 \%$ \\
Region & -0.001 & 0.000 & -0.002 & 0.000 & $0 \%$ & $0 \%$ & $2 \%$ & $0 \%$ \\
Total composition effect & -0.084 & -0.006 & -0.078 & -0.013 & $31 \%$ & $3 \%$ & $83 \%$ & $17 \%$ \\
\hline Total change & -0.274 & -0.180 & -0.094 & -0.076 & $100 \%$ & $100 \%$ & $100 \%$ & $100 \%$ \\
\hline Souce own es \% $\%$ \\
\hline
\end{tabular}

Source: own estimations based on household surveys

\section{Acknowledgements}

We acknowledge funding from the Ministry of Foreign Affairs of Norway. We are thankful for comments and suggestions to previous versions of this paper received in seminars at ECLAC in Santiago de Chile and Instituto de Economía in Uruguay. This research was carried out as part of the regular research program of ECLAC. We would also like to thank the anonymous referee and the editor for the useful remarks.

Responsible editor: Hartmut F. Lehmann

\section{Competing interests}

The IZA Journal of Labor \& Development is committed to the IZA Guiding Principles of Research Integrity. The authors declare that they have observed these principles.

Received: 14 May 2016 Accepted: 31 August 2016

Published online: 13 October 2016

\section{References}

Alves G, Amarante V, Vigorito A (2012) La desigualdad del ingreso en Uruguay entre 1986 y 2009. Instituto de Economía, Facultad de Ciencias Económicas y de Administración, Udelar

Amarante V, Manacorda M, Vigorito A, Zerpa M (2011) Social Assistance and Labor Market Outcomes: Evidence from the Uruguayan PANES, Nota Técnica No. IDB-TN-453, International Development Bank

Amarante V, Colafrancheschi M, Vigorito A (2014) Uruguay's income inequality under right and left regimes over 19812010. In: En Cornia A (ed) Falling Inequalities in Latin America: Policy Changes and Lessons. Oxford University Press Bérgolo M, Cruces G (2014) Work and tax evasion incentive effects of social insurance programs. Evidence from an employment based benefit extension. J Public Econ 117:211-228

Binelli C (2016) Wage inequality and informality: evidence from Mexico. IZA J Labor Dev 5:5

Binelli C, Atanassio O (2010) Mexico in the 1990s: the main cross sectional facts. Rev Econ Dyn 13:238-264

ECLAC (2014) Compacts for equality. Towards a sustainable future. Hacia un Futuro Sostenible, Santiago de Chile

Chong A, Gradstein M (2007) Informality and inequality. J Public Econ 91:159-179

DiNardo J, Fortin N, Lemieux T (1996) Labor market institutions and the distribution of wages, 1973-1992: a semiparametric approach. Econometrica 64(5):1001-1044 
Firpo S, Fortin N, Lemieux T (2007) Decomposing Wage Distributions using Influence Function Projections and Reweighting, mimeo, University of British Columbia

Firpo S, Fortin N, Lemieux T (2011) Decomposition methods in economics. Handbook of Labor Economics 4A:1-97 Gasparini L et al (2012) Educational upgrading and returns to skills in Latin America: evidence from a supply-demand framework, 1990-2010, IZA Discussion Papers, № 6244. Institute for the Study of Labor (IZA), Bonn

Johnson S, Kaufmann D, Zoido-Lobaton P (1998) Regulatory discretion and the unofficial economy. American Economic Review, American Economic Association 88(2):387-92

Llambí C, Perera M (2014) Análisis de la incidencia del mercado de trabajo en la evolucion de la desigualdad de ingresos en Uruguay y en la última década, Background paper for OECD ECLAC Country Report on Uruguay

Llambí C, Rius A, Carrasco P, Carbajal F, Cazulo P (2014) Una evaluación económica de los incentivos fiscales a la inversión en Uruguay. 2005-2011. Centro de Estudios Fiscales, Instituto de Economía de la Facultad de Ciencias Económicas y de Administración y Centro de Investigaciones Económicas

Loayza NV (1996) The economics of the informal sector: a simple model and some empirical evidence from Latin America, vol 45(1), Carnegie-Rochester Conference Series on Public Policy. Elsevier, pp 129-162

Mishra A, Ray R (2013) Corruption and informality, University of Bath Centre for Development Studies Working Paper No. 21

Rosser J, Rosser M, Ahmed E (2000) Income inequality and the informal economy in transition economies. J Comp Econ 28:156-171

Rosser J, Rosser V, Ahmed E (2003) Multiple unofficial economy equilibria and income distribution dynamics in systemic transition. J Post Keynesian Econ 25(3):425-447

Schneider F (2012) The shadow economy and work in the shadow: what do we (not) know? IZA Discussion Paper Series No. 6423

Shneider F, Enste DH (2000) Shadow economies: size, causes, and consequences. J Econ Lit 38(1):77-114

Tornarolli L, Battistón D, Gasparini L, Gluzmann P (2014) Exploring Trends in Labor Informality in Latin America, 1990-2010, CEDLAS, Working Papers 0159. CEDLAS, Universidad Nacional de La Plata

Submit your manuscript to a SpringerOpen ${ }^{\oplus}$ journal and benefit from:

- Convenient online submission

Rigorous peer review

- Immediate publication on acceptance

- Open access: articles freely available online

- High visibility within the field

Retaining the copyright to your article

Submit your next manuscript at $>$ springeropen.com 